\title{
Subversion of inflammasome activation and pyroptosis by pathogenic bacteria
}

\author{
Larissa D. Cunha and Dario S. Zamboni* \\ Department of Cell Biology, Ribeirão Preto Medical School, University of São Paulo (FMRP/USP), Ribeirão Preto, Brazil
}

\section{Edited by:}

Yongqun He, University of Michigan School of Medicine, USA

\section{Reviewed by:}

Mikhail A. Gavrilin, Ohio State

University, USA

Eric Ghigo, Centre National de la

Recherche Scientifique, France

\section{*Correspondence:}

Dario S. Zamboni, Department of Cell Biology, Ribeirão Preto Medical School, University of São Paulo (FMRP/USP), Av. Bandeirantes 3900, Ribeirão Preto, SP 14049-900

Brazil

e-mail: dszamboni@fmrp.usp.br
Activation of the inflammasome occurs in response to a notably high number of pathogenic microbes and is a broad innate immune response that effectively contributes to restriction of pathogen replication and generation of adaptive immunity. Activation of these platforms leads to caspase-1- and/or caspase-11-dependent secretion of proteins, including cytokines, and induction of a specific form of cell death called pyroptosis, which directly or indirectly contribute for restriction of pathogen replication. Not surprisingly, bona fide intracellular pathogens developed strategies for manipulation of cell death to guarantee intracellular replication. In this sense, the remarkable advances in the knowledge of the inflammasome field have been accompanied by several reports characterizing the inhibition of this platform by several pathogenic bacteria. Herein, we review some processes used by pathogenic bacteria, including Yersinia spp., Pseudomonas aeruginosa, Vibrio parahaemolyticus, Chlamydia trachomatis, Francisella tularensis, Shigella flexneri, Legionella pneumophila, and Coxiella burnetii to evade the activation of the inflammasome and the induction of pyroptosis.

Keywords: inflammasome inhibition, pyroptosis, infection control, subversion strategies

\section{INTRODUCTION}

Host pattern recognition receptors (PRRs) are capable of sensing conserved microbial molecules, referred as Pathogen-Associated Molecular Patterns (PAMPs) as well as cellular disturbances, referred as Damage-Associated Molecular Patterns (DAMPs). PRR activation usually leads to induction of pro-inflammatory signaling networks that facilitate direct elimination of the pathogens but also to alert the immune system. Consequently, successful replication of an intracellular infectious agent relies not only on the arsenal of virulence factors that modulate host cell functions to establish a replicative niche, but also in the development of efficient subversion strategies to evade host recognition and bypass the host mechanisms related to restriction of pathogen replication.

Induction of cell death pathways is a conserved host response to infection. However, different subtypes of cell death can be triggered and they will vary according to many factors, e.g., the type of infected cell and the surrounding environment, the infectious agent and the infection dosage. Interestingly, the same mechanism of cell death can elicit either an immunogenic or a tolerogenic ("silent") effect upon the immune system, however, the factors controlling such plasticity remain elusive (Green et al., 2009). Apoptosis, autophagy, and necrosis are still considered the main types of cell death, but several other subtypes can be distinguished based mostly on biochemical and functional criteria (Galluzzi et al., 2012).

Of note, activation of intracellular PRRs belonging to the family of Nod-like receptors (NLRs) or the nucleic acid receptors AIM2 and IFI16 (members of the PYHIN family) trigger a specific type of potentially pro-inflammatory, caspase-1-dependent cell death program known as pyroptosis (Cookson and Brennan, 2001; Lamkanfi and Dixit, 2012). Upon sensing of pathogens, NLRs and AIM2/IFI16 trigger the formation of the inflammasome, a cytosolic molecular platform that recruits and activates caspase-1, initiating a program of pore formation in the plasma membrane of activated cells, with consequent cell rupture and release of cytosolic contents (Martinon et al., 2002; Fink and Cookson, 2006). The activity of caspase- 1 also mediates the activation and controlled secretion of pro-inflammatory cytokines such as IL-1 $\beta$ and IL-18 (Thornberry et al., 1992; Ghayur et al., 1997; Gu et al., 1997). Although pyroptosis and cytokine secretion are both dependent on caspase- 1 and occur concomitantly, it is not confirmed that cytokine release is mediated by induction of cell death pathway. Recently, caspase-11 was shown to mediate a non-canonical pathway of inflammasome activation in response to Gram-negative bacteria, leading to pyroptosis and release of cytokines such as IL-1 $\alpha$ independently of caspase- 1 activation (Kayagaki et al., 2011; Broz et al., 2012; Aachoui et al., 2013; Case et al., 2013; Casson et al., 2013). It was recently demonstrated that intracellular sensing of lipid A motif of lipopolysaccharide (LPS) induces caspase-11-dependent pyroptosis and NLRP3-dependent caspase-1 activation, with subsequent secretion of IL-1 $\beta$ and IL-18 (Hagar et al., 2013; Kayagaki et al., 2013). Most strikingly, detrimental effects of exacerbated inflammation during systemic infectious are possibly mediated by caspase-11, but not caspase-1 (Kang et al., 2002; Kayagaki et al., 2011, 2013; Hagar et al., 2013). This novel caspase-11-mediated inflammasome may operate synergistically with the other caspase-1- mediated inflammasomes for the recognition of pathogenic bacteria encoding type III/type IV secretion systems or escaping the vacuole (Figure 1). 


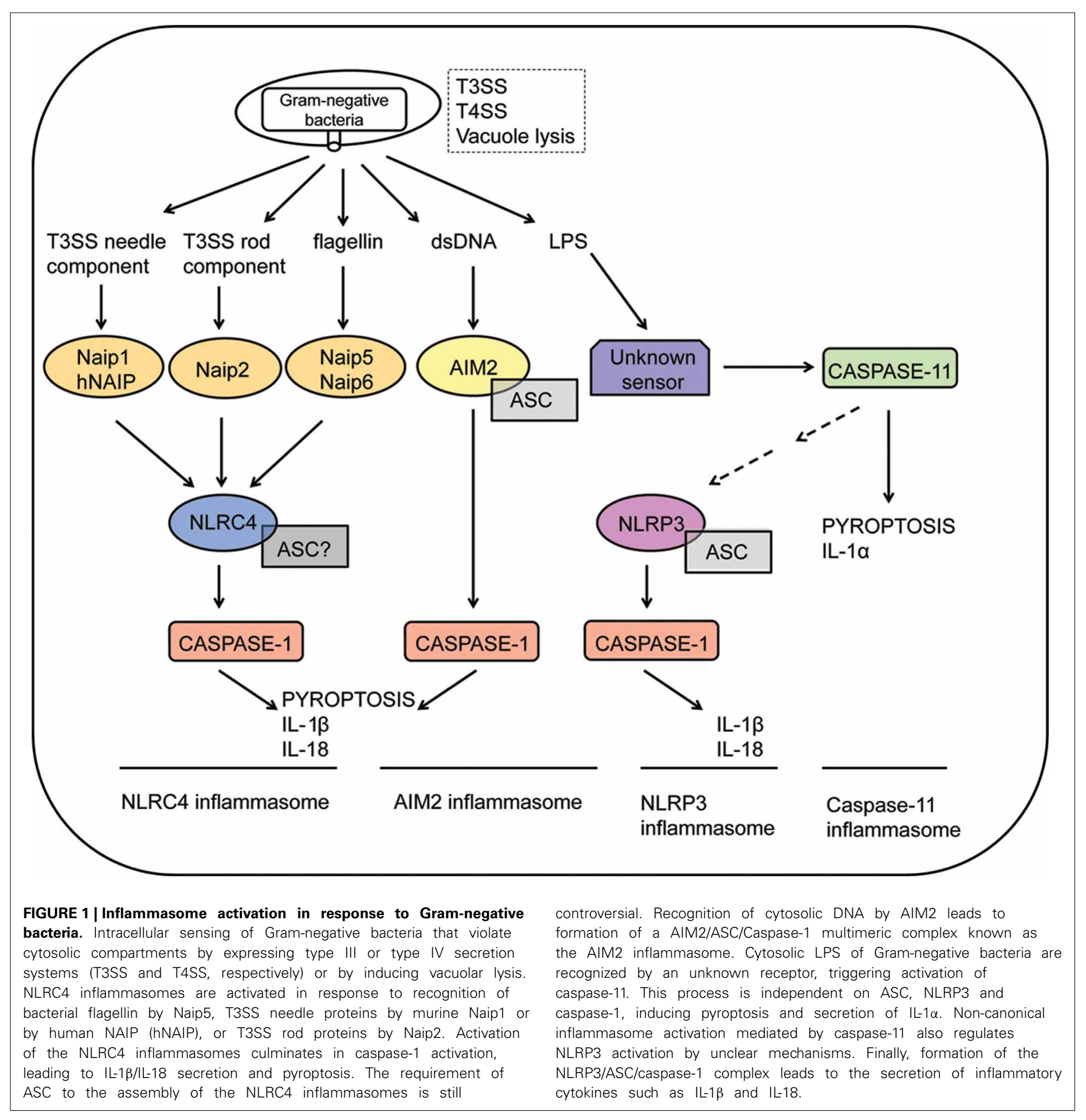

Activation of the inflammasome, with consequent induction of pyroptosis, has been demonstrated for several microbial pathogens (Osawa et al., 2011; Lamkanfi and Dixit, 2012; LimaJunior et al., 2013; Silva et al., 2013). In the case of bacterial pathogens, pyroptosis is a mechanism that effectively contributes to infection control (Miao et al., 2010a, 2011; Terra et al., 2010). Evolutionary pressure thus, shaped modulation of the inflammasome activation, with consequent inhibition of pyroptosis, as a subversion strategy found among microbial pathogens. Bonafide intracellular pathogens (such as bacteria and viruses that modulate host cell functions through secretion systems and secreted proteins) use diverse strategies to evade recognition and inflammasome activation. However, the molecular mechanisms of inflammasome inhibition by pathogens remain largely unknown. Herein, we review the current knowledge on the mechanisms of inflammasome and pyroptosis suppression by pathogenic bacteria. We discuss the importance of inflammasome subversion to their pathogenesis and highlight recent findings on the diverse strategies adopted by bacterial pathogens to inhibit the activation of the inflammasome and how they affect pyroptosis. 


\section{MECHANISMS OF PYROPTOSIS INHIBITION BY BACTERIAL PATHOGENS \\ Yersinia spp.}

The pathogenic Gram-negative bacteria belonging to the genus Yersinia have a tropism to target lymphoid tissues, inducing distinct types of host cell death in the course of infection. The three human pathogens of the genus, Y. pestis, Y. pseudotuberculosis, and $Y$. enterocolitica share a virulence plasmid encoding a conserved type III secretion system (T3SS) and a few identified effector proteins known as Yops (Yersinia outer proteins: YopE, YopT, YopH, YopM, YopA/O, and YopJ/P) (Trosky et al., 2008). The injection of Yops into infected cells allows the modulation of several signaling pathways and immune responses by Yersinia, including cell death. However, as the control of Yersinia multiplication is affected by a complex interplay of distinct types of cell death in different types of infected cells, it is likely that the demise of infected cells not only contributes to pathogenesis but also signals to mount an effective immune response (Philip and Brodsky, 2012). For instance, the early stage of infection is characterized by induction of apoptotic-like death of macrophages and dendritic cells, and YopJ, YopP (the homologous of YopJ in Y. enterocolitica) and YopK have already been implicated in this process, with evidence that apoptosis contributes to bacterial persistence in vivo (Mills et al., 1997; Monack et al., 1997, 1998; Ruckdeschel et al., 1998, 2001; Grobner et al., 2007; Peters et al., 2013). Translocation of YopJ is also implicated in late proinflammatory lytic cell death, independently of caspase-1 (Lilo et al., 2008). Although the molecular mechanisms triggering the inflammasome and caspase- 1 activation in response to Yersinia are largely unknown, recognition of YopJ leads to differential regulation of inflammasome responses. Secretion of IL-1 $\beta$ in response to translocated YopJ requires caspase-1, Nlrp3, and Asc adaptor, whereas caspase-1 activation occurs in the absence of Nlrp3, Nlrc4, and Asc (Brodsky et al., 2010; Zheng et al., 2011). Proinflammatory cell death of infected macrophages mediated by YopJ does not require other inflammasome components such as Nlrp3, Nlrc4, and Asc, corroborating the lack of inflammasome participation in this process (Brodsky et al., 2010; Zheng et al., 2011). Moreover, T3SS recognition also induces caspase- 1 activation and IL- $1 \beta$ secretion, requiring the inflammasome adaptor Asc and mediated by both Nlrp3 and Nlrc4, possibly in synergy (Brodsky et al., 2010). Notably, recognition of Yersinia T3SS also triggers caspase-1 mediated pyroptosis, independently of the effector YopJ, Nlrp3, Asc, and Nlrc4 (Bergsbaken and Cookson, 2007; Brodsky et al., 2010). Diverse effector proteins secreted by T3SS of Yersinia has already been shown to negatively modulate inflammasome activation with associated impairment of pyroptosis in response to Yersinia recognition. This accumulating evidence corroborates that although cell death processes might play different roles in the pathogenesis of Yersinia, evasion of inflammasome activation and inflammatory burst caused by pyroptosis should be important to bacterial success.

Regulation of cytotoxicity by differential secretion of YopJ is one of the processes that impacts virulence of Yersinia. Mutants of Y.pseudotuberculosis lacking YopJ do not induce cell death but fail to disseminate, showing that YopJ is required for optimal virulence (Monack et al., 1998). On the other hand, secretion of reduced levels of YopJ contributes to the pathogenesis of Yersinae in vivo. In this sense, cytotoxicity of dendritic cells induced by Yersinia positively correlated with the level of secretion of YopJ/P, but enhanced cytotoxicity in response to infection with $Y$. pseudotuberculosis ectopically expressing highly secreted YopP reduced virulence in vivo, causing an attenuated infection of the oral mucosa (Brodsky and Medzhitov, 2008). However, recent data demonstrated that caspase-1 deficiency does not impair the control of infection by hypercytotoxic Y. pseudotuberculosis (ectopically expressing YopP) (Zheng et al., 2012). Thus, it is possible that regulation of the levels of YopJ secretion might not be a subversion strategy to downregulate the induction of pyroptosis mediated by YopJ-dependent activation of the inflammasome.

The effectors YopE and YopT, which inactivate Rho GTPases that regulate cytoskeleton rearrangements (Cdc42, Rac1, Rho), were also shown to inhibit secretion of IL-1 $\beta$ in macrophagelike cells infected with Y. enterocolitica (Schotte et al., 2004). YopE also reduced cytotoxicity in these cells. Although YopE and YopT reduce activation of overexpressed caspase- 1 and inhibit cell death in response to caspase- 1 overexpression, the precise mechanism of inhibition of the inflammasome in macrophages has not been examined in detail. In the case of $Y$. pseudotuberculosis, there is no evidence that YopE and YopT play a role in inflammasome modulation (Larock and Cookson, 2012).

The caspase- 1 activation, secretion of IL- $1 \beta$ and pyroptosis mediated by inflammasome recognition of T3SS in infected macrophages was shown to be inhibited by the effector YopK (Brodsky et al., 2010). This protein is secreted into the host cell cytosol and interacts with the T3SS, possibly leading to inhibition of inflammasome activation by impairment of recognition of the bacterial T3SS translocon structure. Activation of the inflammasome by mutants of Y. pseudotuberculosis lacking YopK leads to bacterial clearance in vivo, indicating a role of inflammasome inhibition by YopK in bacterial pathogenesis, promoting pathogen multiplication and dissemination. However, whether virulence mediated by inhibition of the inflammasome by YopK requires regulation of pyroptosis is yet only suggestive.

A recent report revealed that Yersinia also directs inhibition of caspase-1 and consequent inhibition of pyroptosis in infected macrophages through aT3SS-dependent effector (Larock and Cookson, 2012). The effector YopM binds to the active site of caspase-1 through a four amino acid motif similar to the sequence of the caspase- 1 substrate YVAD and poxvirus protein CrmA, thus, sequestering the molecule and abrogating its interaction with the molecular platform formed by Nlrp3 and Asc in infected macrophages. Inhibition of caspase- 1 activation by YopM impaired induction of pyroptosis, demonstrating that the effector modulates inflammatory cell death during infection. Importantly, absence of YopM impaired virulence of Y. pseudotuberculosis in vivo, suggesting that inhibition of caspase-1-dependent cell death and cytokine secretion should play a role in the pathogenesis of Yersinia.

How regulation of different types of cell death by Yersinia, i.e., apoptosis, pyroptosis and possibly necrosis, determines the balance between promotion of effective immune responses and successful immunomodulation, dissemination, and growth of the pathogen is yet to be understood. 


\section{Pseudomonas aeruginosa}

The Gram-negative bacterium $P$. aeruginosa is an opportunistic extracellular pathogen ubiquitously found in the environment. Antibiotic-resistance and vast distribution make $P$. aeruginosa a major source of nosocomial acute infection of immunocompromised individuals and infection associated to the use of contaminated medical devices. $P$. aeruginosa is also often associated to the infection of chronic cystic fibrosis patients (Garau and Gomez, 2003). The bacteria express a functional T3SS through which four known effectors, exoenzyme S (ExoS), ExoT, ExoU, and ExoY are secreted into host cell (Engel and Balachandran, 2009). Of note, expression of the exoenzymes varies among the different strains of $P$. aeruginosa (Engel and Balachandran, 2009). Activity of these effectors trigger signaling cascades, such as synthesis of cAMP (ExoY), cleavage of phospholipids (ExoU), and modulation of cytoskeleton dynamics (ExoS, ExoT, ExoU) that potentially can lead to activation of cell death pathways, although cytotoxic effects have been described to ExoS and ExoU only (Pederson and Barbieri, 1998; Sato and Frank, 2004).

The contribution of the inflammasome to recognition of $P$. aeruginosa by macrophages has been extensively described. The Nlrc4 receptor plays a major role in activation of caspase- 1 in macrophages infected with pathogenic bacteria. Activation of the Nlrc4 inflammasome is triggered upon recognition of bacterial flagellin and the T3SS secretion system (Franchi et al., 2007; Sutterwala et al., 2007; Galle et al., 2008; Miao et al., 2008). Recognition of the T3SS rod component also occurs, dependent on Nlrc4 in a process mediated by activation of theNaip2 protein (Miao et al., 2010b; Zhao et al., 2011). Moreover, a toxin encoded by the $r h s T$ gene of $P$. aeruginosa induces inflammasome activation and cytotoxicity in response to the bacteria, contributing to bacterial clearance in vivo (Kung et al., 2012). Activation of Nlrc4 inflammasome in response to $P$. aeruginosa mediates pyroptotic cell death and IL- $1 \beta$ secretion. Both processes have been shown to contribute to control of infection in vivo, although recent data argues that neutrophils, instead of macrophages, are the main source of IL- $1 \beta$ in infected mouse. Moreover, the IL-1 $\beta$ production by neutrophils occurs independently of bacterial flagellin, Nlrc4 or caspase-1 (Karmakar et al., 2012; Cohen and Prince, 2013). Thus, the contribution of the inflammasome to control of infection by $P$. aeruginosa may be further investigated.

Importantly, the T3SS-dependent effector proteins of $P$. aeruginosa have been shown to inhibit the inflammasome activation in macrophages both in vitro and in vivo. From the four described effectors secreted by $P$. aeruginosa T3SS, ExoS, and ExoU inhibit inflammasome-dependent responses, arguing that if not inhibited this pathway can play a pivotal role in immune responses and bacterial clearance.

It has been shown that ExoS deficiency leads to the secretion of cleaved IL-1 $\beta$ in both alveolar macrophages and in the lungs of mice infected with $P$. aeruginosa (Galle et al., 2008). ExoS is a bifunctional protein containing an amino-terminal Rho GTPase Activating Protein (GAP) domain, which modifies host cell targets that control the cytoskeleton, such as Cdc42, Rho and Rac1; and a carboxy-terminal ADP-ribosyltransferase domain (ADPRT) with ribosylation activity causing cytoskeleton rearrangements. Of note, the ADPRT domain, but not the GAP domain of ExoS, is essential to inhibition of IL-1 $\beta$ mediated by the exoenzyme. The importance of ribosylation activity of ExoS in this process allows speculating that modulation of host cell cytoskeleton dynamics is a possible mechanism through which ExoS inhibits the inflammasome. For instance, it has been recently reported that organelle transportation activity of microtubules is critical for activation of the inflammasome mediated by Nlrp3 (Misawa et al., 2013). Finally, ExoS induces caspase-3 dependent apoptotic cell death in response to infection but pro-inflammatory death of macrophages is also increased in the infection of macrophages with mutants lacking ExoS. Whether this effect is due to a putative ExoS-mediated inhibition of caspase-1-dependent pyroptosis or caused by cytotoxic effects independent of inflammasome activation has yet to be addressed.

For ExoU, it has been demonstrated that this exoenzyme inhibits Nlrc4-dependent caspase- 1 activation and IL- $1 \beta$ in a process dependent on its phospholipase A2 activity (Sutterwala et al., 2007). However, pyroptosis triggered by Nlrc4 and caspase- 1 was not modulated by ExoU, which is suggestive that the cytotoxic effect induced by the exotoxin may be due to non-apoptotic, caspase-1-independent necrosis (Sutterwala et al., 2007).

In summary, whether pyroptosis is involved in the pathogenesis of $P$. aeruginosa or whether it contributes to an efficient immune response by the host is still uncertain. However, differential induction and modulation of specific cell death pathways by the exotoxins of the pathogen, as well as clear inhibition of specific responses of the inflammasome by them, make $P$. aeruginosa a valuable model to investigate the role of different cell death pathways to the outcome of host-pathogen interaction and thus, should be further explored.

\section{Vibrio parahaemolyticus}

Pathogenicity of V. parahaemolyticus, a Gram-negative extracellular bacterium associated mostly with seafood-borne gastroenteritis, relies on the expression of two thermostable pore-forming hemolysins (TDHs, namely TdhA and TdhS) and two sets of chromosome-encoded T3SS (T3SS-1 and T3SS-2) (Makino et al., 2003). A recent report demonstrated that V. parahaemolyticus has been shown to induce robust activation of the inflammasome dependent on multiple mechanisms (Higa et al., 2013). V. parahaemolyticus TDHs activate Nlrp3-dependent inflammasome (mainly through recognition of TdhA) and bacterial T3SS-1 induces inflammasome activation mediated by both Nlrp3 and Nlrc4. In addition, bacterial flagellin triggers the Nlrc4 inflammasome. Notably, recognition of TDHs and T3SS-1 were required to induce caspase-1-dependent pyroptosis in response to infection. In addition, inflammatory cell death independent of caspase1 was also observed, suggesting that other pathways may be involved in the induction of cell death in response to $V$. parahaemolyticus. Notably this same report described a regulatory role for inflammasome activation mediated by the T3SS effectors VopQ and VopS, encoded in the pathogenicity island $h 1$ of Chromosome I. VopQ and VopS inhibited activation of the Nlrc4dependent inflammasome upon recognition of T3SS-1. VopQ and VopS synergize to inhibit cleavage of caspase- 1 and secretion 
of cleaved IL-1 $\beta$, but any effect on pyroptosis has yet to be determined. In fact, complete deletion of $h 1$ decreased pyroptosis in response to infection, suggesting that other effectors of the bacteria also encoded in the region $h 1$ may be important for specific induction of pyroptosis by $V$. parahaemolyticus.

The effector VopQ is also known to be a determinant to the induction of autophagy in HeLa cells infected with V. parahaemolyticus (Burdette et al., 2009). Higa et al. (2013) demonstrated that VopQ induced autophagy in murine macrophages in response to infection. In addition, suppression of autophagic pathway by knocking down of Atg5 impaired the inhibition of IL-1 $\beta$ secretion mediated by VopQ, supporting a possible role of autophagy in inflammasome inhibition by VopQ. Importantly, induction of autophagy has been previously shown to negatively regulate inflammasome activation dependent on Nlrp3 (Saitoh et al., 2008). How the induction of autophagy mediated by VopQ could possibly mediate inflammasome suppression by the effector remains elusive, but it is possible that Nlrc4-mediated inflammasome activation may also be regulated by autophagy.

In the case of VopS, it is observed that the effector binds and inactivates endogenous $\mathrm{Cdc} 42$, which could account as a mechanism for inhibition of Nlrc4-inflammasome (Higa et al., 2013). As mentioned above, inhibition of inflammasome responses by the effectors ExoS of $P$. aeruginosa and YopE of Y. enterocolitica relies on their GAP activity that mediates inactivation of Rho GTPases (Schotte et al., 2004; Galle et al., 2008). No molecular role for regulation of inflammasome activation by active Rho GTPases has been demonstrated yet, but evidence suggests that these molecules may participate in inflammasome activation in response to pathogens. For instance, the SP-1 effector SopE of Salmonella enterica serovar Typhimurium, an activator of Rho GTPases induces inflammasome activation by stromal cells in response to bacterial recognition (Muller et al., 2009). Importantly, activation of caspase- 1 by SopE requires modulation of Racl and Cdc42 by the bacterial effector. Another recent report revealed that activation of Racl in response to infection is important to NLRP3/ASC-dependent caspase-1 activation in response to Chlamydia pneumoniae by human mononuclear cells (Eitel et al., 2012). Importantly, a recent work showed that type I IFN signaling inhibits Rac1, with consequent repression of Nlrp3 inflammasome in macrophages (Inoue et al., 2012). These evidences reinforce a putative role of signaling pathways controlled by Rho GTPases in the modulation of inflammasome activation in response to pathogens, possibly inducing pyroptosis. How the activity of Rho GTPases in inflammasome activation, as well as modulation as a subversion strategy targeting immune responses may thus, be further explored.

\section{Chlamydia trachomatis}

The obligate intracellular Gram-negative pathogen C. trachomatis is the causative agent of infections of the conjunctiva and urogenital tract commonly evolving to severe complications such as blindness, pelvic inflammatory disease, ectopic pregnancy, and infertility. The bacteria rely on the expression of a T3SS and secretion of effector proteins to adhere, invade, and establish a replicative inclusion (parasitophorous vacuole) in the target cells (Valdivia, 2008; Betts et al., 2009). Besides the T3SS-dependent effectors protein, the chlamydial protease-like activity factor (CPAF) is pivotal in the molecular pathogenesis of C. trachomatis, modulating host responses and stability of bacterial inclusion (Paschen et al., 2008). CPAF is translocated through the general secretory pathway, eventually reaching the host cell cytosol (Zhong et al., 2001). This effector is suggested to regulate by cleavage at least 16 host targets, interfering with several processes such as: proapoptotic signaling (Zhong et al., 2001; Pirbhai et al., 2006); expression of antigen presentation molecules (MHC) (Zhong et al., 2001); organization of host cell cytoskeleton (Dong et al., 2004; Kumar and Valdivia, 2008); control of cell cycle (Paschen et al., 2008) and NF-кB signaling pathway (Christian et al., 2010). Although host substrates were demonstrated to be cleaved by CPAF in cell lysates, enzymatic activity of CPAF may not be necessarily required in situ to exert its regulatory functions on host cell proteins (Chen et al., 2012). Nevertheless, CPAF has also been implicated in modulation of chlamydial proteins. It has been demonstrated that CPAF cleaves chlamydial T3SSdependent effectors in cell-free systems and in infected cells, with evidences that CPAF proteolytic activity toward C. trachomatis effectors prevents superinfection and coordinates the formation and the integrity of the inclusion-containing the bacteria (Jorgensen et al., 2011).

In epithelial cells, which are the primary sites of infection by C. trachomatis, as well as in human monocytes and dendritic cells, NLRP3 and ASC mediate inflammasome-dependent activation of caspase- 1 and secretion of cytokines in response to C. trachomatis (Lu et al., 2000; Gervassi et al., 2004; Abdul-Sater et al., 2009, 2010). However, the role of the inflammasome in the control of the infection by the pathogen is still controversial. Asc- and caspase-1-deficient mouse fibroblasts are resistant to infection by C. trachomatis (Jorgensen et al., 2011). In addition, in a mouse model of infection with $C$. muridarum, wild-type and caspase-1 deficient mice equally controlled the replication of the bacteria in vivo (Cheng et al., 2008). Of note, caspase-1-deficient mice displayed reduced inflammatory damage in the urogenital tract, suggesting that inflammasome activation may contribute to the pathology of infection by Chlamydia (Cheng et al., 2008).

Still, C. trachomatis regulates caspase-1-dependent cell death through the activity of CPAF. The use of a specific inhibitor of CPAF, design to overcome the refraction of the bacteria to genetic manipulation, revealed that CPAF activity inhibits ASC and caspase-1-dependent cell death in the early times of infection of epithelial cells with C. trachomatis. Late activation of caspase1 occurs in epithelial cells and pharmacological inhibition of caspase-1 reduces bacterial growth in these cells, corroborating the importance of regulation of inflammasome activation to the pathogenesis of C. trachomatis (Abdul-Sater et al., 2009). However, a role for pyroptosis for caspase-1-dependent susceptibility to infection is still speculative. The mechanism of inhibition of early pyroptotic cell death by CPAF is yet to be understood and it is not ruled out that the protease directly interferes with inflammasome formation. Still, one interesting possibility proposed by Jorgensen et al. (2011) is that CPAF may function as a metaeffector (Kubori et al., 2010), regulating the pool of T3SS effectors in the host cytosol by proteolysis and also avoiding the accumulation of putative PAMPs to be sensed by cytosolic NLRs, possibly 
providing a novel mechanism of pathogenic modulation of the inflammasome.

\section{Francisella tularensis}

Tularemia, a life-threatening infectious disease of the respiratory tract, is caused by the Gram-negative intracellular pathogen Francisella tularensis. Inside infected macrophages, the main target of infection, F. tularensis escapes the vacuole and replicates within the cytosol. However, in contrast to most of the intracellular pathogens, the bacteria do not rely on the activity of exotoxins or encoded T3SS and T4SS secretion systems and related effectors to modulate host cell functions (Larsson et al., 2005), and virulence mechanisms of the pathogen remain largely unknown (Broms et al., 2010; Meibom and Charbit, 2010). The inflammasome plays a pivotal role in recognition and control of infection by $F$. tularensis in experimental models of infection. The bacteria trigger activation of Aim2/Asc-dependent inflammasome in mouse macrophages (Mariathasan et al., 2005; FernandesAlnemri et al., 2010; Jones et al., 2010; Rathinam et al., 2010). Recognition of the bacteria by this Aim2/Asc leads to activation of caspase- 1 , secretion of IL- $1 \beta$ and IL-18, pyroptosis and culminate in the control of bacterial replication in macrophages and in vivo. In addition, Aim 2 and Asc were proposed to trigger caspase-1-independent, caspase-8, -9, -3-mediated apoptosis of macrophages in response to infection with $F$. tularensis, contributing to restriction of bacterial replication in these cells (Pierini et al., 2012). Finally, whereas Nlrp3 is dispensable for inflammasome activation in murine macrophages, NLRP3 and AIM2 are suggested to play a role in human monocytic cells (Mariathasan et al., 2006; Fernandes-Alnemri et al., 2010; Jones et al., 2010; Atianand et al., 2011).

Absence of Aim 2 activation by $m v i N$ and ripA mutants of F. tularensis have been initially reported (Huang et al., 2010; Ulland et al., 2010), but the lack of these encoded factors was shown to compromise the integrity of bacteria and enhance intramacrophage lysis of mutant bacteria and release of DNA into the host cell cytosol (Peng et al., 2011). Besides mviN and ripA, mutations on core components of the type VI secretion system of F. tularensis also affect activation of the inflammasome (Barker et al., 2009; Broms et al., 2012), therefore, it is still possible that this lack of activation may be due to an inherited defect in phagosome escape of this bacteria.

Recent data, however, suggests that the bacteria actively repress inflammasome signaling by the effector protein encoded by FTL_0325, a process that may contribute to repression of IL-1 $\beta$ secretion and bacterial growth in vivo (Dotson et al., 2013). The authors observed that virulent F. tularensis subsp. tularensis and holarctica fail to induce a robust activation of the inflammasome in the early times of the infection in comparison to attenuated $F$. tularensis subsp. novicida. Mutations in FTL_0325 gene of F. tularensis subsp. holarctica (live vaccine strain -LVS) do not alter bacterial fitness whilst it exacerbates the synthesis of pro-IL-1 $\beta$. In addition, mutants lacking FLT_0325 also induce higher levels of caspase-1 activation dependent on Aim 2 and Tlr 2 and secretion of IL- $1 \beta$ dependent on Tlr2, Aim2, and Nlrp3 in the early periods of infection. Importantly, suppression of Aim2-dependent inflammasome activation by
FLT_0325 inhibits pyroptosis in response to infection by $F$. tularensis LVS in macrophages (Dotson et al., 2013). Whether pyroptosis repression contributes to pathogenesis in vivo is still unclear.

\section{Shigella flexneri}

Bacillary dysentery in humans is caused by mucosal infection with the Gram-negative intracellular pathogen S. flexneri. The bacteria express a functional T3SS, through which sequential delivery of bacterial effectors into host cell cytosol promotes pathogenesis (Ogawa et al., 2008). In addition, recognition of S. flexneri PAMPs elicits immune responses that paradoxically contribute to bacterial success (Phalipon and Sansonetti, 2007). Shigella invades the epithelia through the $\mathrm{M}$ cells of the mucosa barrier, subsequently infecting resident macrophages and dendritic cells. Once within these cells, the bacteria lyse the vacuole, replicates in the host cell cytosol and eventually triggers inflammatory cell death. This inflammatory burst and consequent neutrophil recruitment promotes basolateral invasion and dissemination of S. flexneri, followed by their entry into epithelial cells, renewed replication of bacteria and further dissemination along the epithelia using a cell-to-cell spread mechanism. However, the infection of epithelial cells generates an early genotoxic stress that could potentially cause necrotic death and bacterial control; bacterial replication inside these cells, suggests that Shigella also antagonizes cell death. In this way, S. flexneri concerted modulation of pro-death and pro-survival signaling pathways potentially allow bacterial circulation among different host compartments, maintenance of a replicative niche and a mechanism to circumvent the innate immune response (Schroeder and Hilbi, 2008; Ashida et al., 2011).

Signaling through Nlrc4inflammasome pathway, mediated by recognition of the rod component MxiI of the T3SS apparatus culminates in caspase- 1 activation, pyroptosis and IL- $1 \beta$ and IL-18 secretion (Suzuki et al., 2007; Miao et al., 2010b). The T3SS effector protein IpaB also induces pyroptosis and IL-1 $\beta$ dependent on caspase-1 (Chen et al., 1996; Hilbi et al., 1998). Although physical interaction of caspase-1 and IpaB has been demonstrated, recent data support a mechanism of ion channel formation by oligomerization of IpaB in the host cell membrane, possibly inducing Nlrc4 and Asc-dependent inflammasome activation that culminates into caspase- 1 activation and pyroptosis (Senerovic et al., 2012). Inflammasome activation in infected macrophages, caspase-1 activation, pyroptosis and secretion of inflammatory cytokines can correspond to the inflammatory burst associated to shigellosis. Importantly, inflammatory burst induced by $S$. flexneri, associated with bacterial invasion and dissemination as well as resolution of infection by a competent host, requires caspase-1, IL-1 $\beta$, and IL-18 (Sansonetti et al., 1995, 2000). It is likely that fine modulation by Shigella of pyroptosis in infected macrophages could favor bacterial basolateral dissemination but avoid the potential restriction of infection associated with robust immune signaling. Nonetheless, a specific molecular mechanism underlying this putative process has not yet been revealed.

In the case of nonmyleoid epithelial cells, acute infection by Shigella induces necrotic cell death pathways as a consequence 
of mitochondrial damage as well as due to genotoxic stress through activation of calpain. The activation of calpain is a process mediated by the bacterial effector VirA with complex consequences, promoting bacterial uptake, inhibition of early pro-apoptotic signaling by degradation of p53 but also induction of late necrosis that contributes to invasion (Bergounioux et al., 2012). However, death of infected cells is supposed to be modulated by the bacteria to support intracellular bacterial growth inside epithelial cells thus, favoring primary tissue colonization. In this sense, activation of pro-survival NF- $\mathrm{B}$ signaling pathway through recognition of bacterial PAMPs by Nod1 and Rip2 possibly counterbalances necrotic cell death (Carneiro et al., 2009).

A recent report revealed that mutants of S. flexneri lacking the expression of the T3SS effector protein OspC3 induce early pyroptotic cell death upon infection by $S$. flexneri of human epithelial cell lines (Kobayashi et al., 2013). In agreement, $\Delta$ ospC3 $S$. flexneri increases mucosal cell death and inflammatory infiltrate in the intestine of infected guinea pigs, with associated reduction of bacterial growth in the epithelia without affecting bacterial invasiveness. Of note, pyroptosis induced by $\triangle \operatorname{ospC3S}$. flexneri specifically requires caspase-4, the human homolog of murine caspase-11, but not caspase-1. OspC3 reduces catalytic activity of caspase-4, also decreasing cell death induced by overexpression of p19 catalytic subunit of casp-4. Caspase- 4 physically interacts with OspC3 through the catalytic site in the p19 subunit of the active caspase-4. Interaction and inhibition of pyroptosis induced by caspase- 4 also requires the C-terminal Ankyrin repeat-containing domain of OspC3 (ANK), a eukaryotic-like domain predicted to mediate protein-protein interactions. Most strikingly, certain motifs in the ANK domain of OspC3 share high similarity to other bacterial and viral proteins, including those encoded by Legionella pneumophila, Coxiella burnetii, Rickettsia rickettsia, and vaccinia virus. This first demonstration of a pathogen effector protein that inhibits non-canonical induction of pyroptosis is suggestive that this mechanism might be a common strategy to modulate the induction of inflammatory responses among diverse pathogens. In the case of Shigella, it is likely that inhibition of caspase-4-dependent pyroptosis provides both the maintenance of epithelial replicative niche as well as evasion of early immune signaling.

\section{Legionella pneumophila}

L. pneumophila is a Gram-negative intracellular bacterial pathogen that accidentally infects humans, causing a pneumonialike disease in immunocompromised individuals. The pathogen resides within a cytosolic endosomal replicative vacuole (LCV), avoiding fusion with lysosomal vesicles and modulating diverse host cell functions to maintain the replicative niche. To this end, L. pneumophila secretes through a type IVB secretion system called Dot/Icm (Defective organelle trafficking/Intracellular multiplication) more than 300 effectors proteins into the host cell cytosol, which are mostly involved in the maintenance of the LCV and bear wide function redundancy (Hubber and Roy, 2010).

L. pneumophila is known to induce robust activation of the inflammasome by triggering different pathways. Bacterial flagellin secreted through the Dot/Icm system into host cell cytosol is recognized by the Naip5-Nlrc4-caspase-1 axis, triggering pyroptosis and Asc-dependent secretion of IL-1 $\beta$ (Amer et al., 2006; Molofsky et al., 2006; Ren et al., 2006; Zamboni et al., 2006; Lightfield et al., 2008; Case et al., 2009; Silveira and Zamboni, 2010). Of note, flagellin recognition via Naip5/Nlrc4/caspase-1 account to infection control in vitro and in vivo (Amer et al., 2006; Molofsky et al., 2006; Ren et al., 2006; Zamboni et al., 2006; Coers et al., 2007; Pereira et al., 2011). Moreover, data suggests that activation of caspase-7 dependent on this inflammasome pathway leads to LCV acidification and fast macrophage death, contributing to bacteria control in vitro (Akhter et al., 2009). In addition, Dot/Icm products induce flagellin-independent inflammasome activation regulated by caspase-11. Caspase- 11 mediates macrophage pyroptosis and secretion of IL- $1 \alpha$, besides regulating Nlrp3/Asc-dependent secretion of IL-1 $\beta$ (Case et al., 2013). Importantly, evidence suggests that inflammasome-dependent pyroptosis and neutrophil recruitment mediate by IL- $1 \beta$ and IL$1 \alpha$ are important to bacterial clearance (Casson et al., 2013). Recently, secretion of IL- $1 \alpha$ independent of caspase- 1 and caspase-11 has also been shown to participate in neutrophil recruitment and infection control (Barry et al., 2013).

In contrast to the current knowledge on inflammasome activation by L. pneumophila, little is known about mechanisms of inflammasome subversion by the pathogen. Of note, L. pneumophila evolved cycling through different unicellular amebae protozoa in freshwater reservoirs, possibly conserving features that allow a broad host-range pathogen instead of those specific to provide resilience in specialized phagocytes (Ensminger et al., 2012). In this sense, the course of pathogen adaptation to adequate host, L. pneumophila may have encountered little selective pressure to evade PRRs recognition and immune responses (Massis and Zamboni, 2011). Consequently, it is possible that a reduced number of L. pneumophila effectors should be involved in subversion of innate immune responses of host macrophages such as inflammasome activation and pyroptosis, favoring the conservation of tools to hijack vesicles and organelles necessary to constant remodeling of the LCV. On the other hand, the recent description of a putative primitive immune-like system encoded in the genome of Acanthamoeba castellanii (Clarke et al., 2013) raises the possibility of existence of environmental pressure that could have favored natural selection of bacteria provided with evasion mechanisms against host immune response.

Of note, upregulation of non-apoptotic genes by activation of NF- $\kappa \mathrm{B}$ in a Dot/Icm-dependent manner counterbalance the activation of caspase-3-mediated apoptotic pathway upon infection, indicating that L. pneumophila can modulate host cell death (Abu-Zant et al., 2005, 2007). Early activation of caspase-3 is induced by multiple bacterial secreted effectors and plays a role in the arrested maturation of nascent bacteria-containing phagosome through the endocytic pathway (Gao and Abu Kwaik, 1999; Zink et al., 2002; Molmeret et al., 2004; Zhu et al., 2013). Importantly, caspase-3 activation accounts for restriction of bacterial replication in dendritic cells (Nogueira et al., 2009). Although direct inhibition of the inflammasome and pyroptosis by L. pneumophila effector proteins has not yet been demonstrated, the Dot/Icm effector SdhA is required for bacterial replication in macrophages (Laguna et al., 2006). SdhA is 
important to avoid Aim2-dependent inflammasome activation in response to recognition of L. pneumophila DNA (Ge et al., 2012). Macrophages infected with mutants lacking $s d h A$ gene trigger Aim2-dependent activation of caspase-1, secretion of IL-1 $\beta$ and pyroptosis, which is reversible by infection with genetically complemented bacteria. However, as in the case of $F$. tularensis and the genes $m v i N$ and ripA, it will be important to determine whether the activation of Aim2 inflammasome in response to infection with $s d h A$ mutants is not an indirect effect of bacterial DNA release in the cytosol as a consequence of compromised integrity of LCV and bacterial degradation. Interestingly, a recent report suggested that induction of autophagosome turnover dependent on recognition of virulent flagellate L. pneumophila through Naip5/Nlrc4/pro-caspase-1 regulates pyroptosis triggered by the same pathway (Byrne et al., 2013). However, the mechanism by which inflammasome components promote the autophagic flux and how the induction of autophagy regulates pyroptosis remain elusive. Paradoxically, L. pneumophila inhibits autophagy through irreversible inactivation of Atg8 mediated by the effector RavZ (Choy et al., 2012). Whether autophagy contributes to infection or boosts immunity in response to L. pneumophila should be further explored.

\section{Coxiella burnetii}

Similarly to Legionella pneumophila, the Gram-negative, obligate intracellular bacteria and human pathogen Coxiella burnetii express the unique type IVB Dot/Icm secretion system (McDonough et al., 2012). Although the two pathogens are also closely related in phylogenetic analysis, C. burnetii is a bonafide mammalian pathogen, with a strong tropism for alveolar macrophages in infected humans. Their distinct natural history is evident in the strikingly divergent life style adopted by the bacteria once inside the host cells. C. burnetii demands an acidified environment for morphological development, Dot/Icm expression and replication, which is accomplished by active maturation of bacteria-containing vacuole through the endosomal pathway, culminating in fusion with recruited lysosomal vesicles and formation of a large replicative vacuoles (LRV) (Newton and Roy, 2011). Of note, C. burnetii is capable of modulating several cellular processes to both remodel the LRV as well as to escape bacterial recognition and control. The genome of $C$. burnetii encodes more than 200 putative candidates for Dot/Icm secretion, of those roughly $25 \%$ have been shown to be effectively expressed and secreted in to host cell cytosol, with just a few with a demonstrated functionality (Van Schaik et al., 2013). It is possible that functional redundancy among C. burnetii effectors is reduced in comparison to L. pneumophila, as diverse genes have already been shown to affect LRV formation (Weber et al., 2013).

The mechanism of recognition and immune response to C. burnetii in macrophages remains elusive. Variations in the $\mathrm{O}$-antigen of $C$. burnetii LPS are determinant to the virulence of the bacteria, with avirulent organisms expressing a truncated form of O-antigen in the LPS structure. Besides, differences in antigenic reactivity of $C$. burnetii LPS is determined by variation in the chemical composition of the $\mathrm{O}$-polysaccharide chain

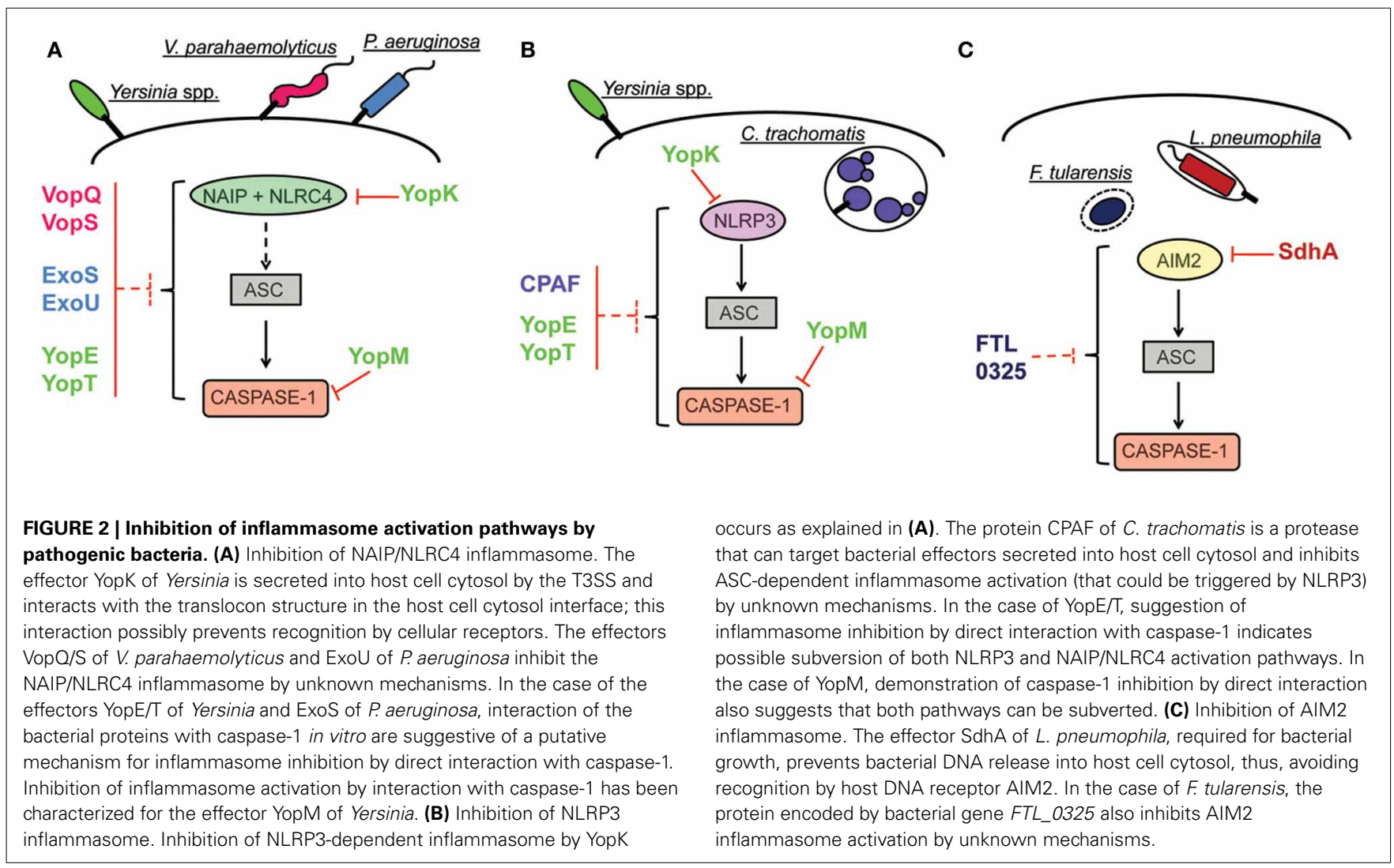


Table 1 | Summary of bacterial effectors that suppress inflammasome activation and their role on suppression of pyroptosis, as discussed in the main text.

\begin{tabular}{|c|c|c|c|c|c|}
\hline & Bacterial effector & $\begin{array}{l}\text { Mechanism of } \\
\text { inflammasome } \\
\text { inhibition }\end{array}$ & Inflammasome target & $\begin{array}{l}\text { Effect on } \\
\text { macrophage } \\
\text { pyroptosis }\end{array}$ & References \\
\hline \multirow[t]{4}{*}{ Yersinia spp. } & YopK & $\begin{array}{l}\text { Interaction with } \\
\text { YopK possibly } \\
\text { prevents } \\
\text { recognition of } \\
\text { T3SS }\end{array}$ & Metaeffector & Inhibition & Brodsky et al., 2010 \\
\hline & YopE (Y. enterocolitica) & $\begin{array}{l}\text { Unknown, YopE } \\
\text { interacts with } \\
\text { caspase-1 } \\
\text { in vitro }\end{array}$ & Unknown & Inhibition & Schotte et al., 2004 \\
\hline & YopM & $\begin{array}{l}\text { Direct inhibition } \\
\text { of caspase-1 } \\
\text { activation }\end{array}$ & Caspase-1 & Inhibition & Larock and Cookson, 2012 \\
\hline & YopT (Y. enterocolitica) & $\begin{array}{l}\text { Unknown, YopT } \\
\text { interacts with } \\
\text { caspase-1 } \\
\text { in vitro }\end{array}$ & Unknown & Not-described & Schotte et al., 2004 \\
\hline \multirow[t]{2}{*}{$P$. aeruginosa } & Exos & $\begin{array}{l}\text { Unknown, } \\
\text { dependent on } \\
\text { ribosylation } \\
\text { activity of ExoS }\end{array}$ & Unknown & Not-described & Galle et al., 2008 \\
\hline & ExoU & $\begin{array}{l}\text { Unknown, } \\
\text { dependent on } \\
\text { phospholipase } \\
\text { activity of ExoU }\end{array}$ & Unknown & No inhibition & Sutterwala et al., 2007 \\
\hline \multirow[t]{2}{*}{ V. parahaemolyticus } & VopQ & $\begin{array}{l}\text { Unknown, } \\
\text { dependent on } \\
\text { host cell } \\
\text { autophagy }\end{array}$ & Unknown & Not described & Higa et al., 2013 \\
\hline & VopS & $\begin{array}{l}\text { Unknown, } \\
\text { dependent on } \\
\text { inhibition of Rho } \\
\text { GTPase byVopS }\end{array}$ & Unknown & Not described & Higa et al., 2013 \\
\hline C. trachomatis & CPAF & $\begin{array}{l}\text { Unknown, } \\
\text { requires } \\
\text { proteolytic } \\
\text { activity of CPAF }\end{array}$ & Unknown & Inhibition & Jorgensen et al., 2011 \\
\hline F. tularensis & FTL_0325 & Unknown & Unknown & Inhibition & Dotson et al., 2013 \\
\hline S. flexneri & OspC3 & $\begin{array}{l}\text { Direct inhibition } \\
\text { of caspase- } 4\end{array}$ & Caspase-4 & Inhibition & Kobayashi et al., 2013 \\
\hline L. pneumophila & SdhA & $\begin{array}{l}\text { Inhibition of } \\
\text { bacterial DNA } \\
\text { release }\end{array}$ & AIM2 & Inhibition & Ge et al., 2012 \\
\hline
\end{tabular}

(Narasaki and Toman, 2012). Although the bacterial lipopeptides are recognized by Tlr2, as demonstrated with infections performed purified molecules and with avirulent phase II C. burnetii (Zamboni et al., 2004), the virulent phase I bacteria avoid
Tlr2 recognition by forming a protective structure that avoids exhibition of components of the bacteria cell wall for Tlr2 recognition (Shannon et al., 2005). In addition, the structure of the lipid A of the LPS of C. burnetii was also revealed and it was 
shown that lipid A derived from both virulent and avirulent bacteria antagonizes Tlr4 activation (Zamboni et al., 2004). Of note, antagonic engagement of Tlr4 by C. burnetii LPS is possibly a complex process. A recent report showed that virulent bacteria and their LPS trigger an impaired activation of the MAPK pathway in macrophages, which is important to avoid conversion of phagolysosomes hosting bacteria into degradative compartments containing cathepsin D (Barry et al., 2012).

The bacterium is also known to induce pro-survival pathways that sustain bacterial growth. Phase I and phase II C. burnetii induce sustained phosphorylation of anti-apoptotic host proteins Akt and Erk1/2 (Voth and Heinzen, 2009). Interaction of Beclin-1, a protein of autophagy, with anti-apoptotic Bcl2 in the membrane of the bacterial LRV prevents apoptosis of cells infected with C. burnetii (Vazquez and Colombo, 2010). In addition, $C$. burnetii inhibits caspase-3- dependent intrinsic pathway of apoptosis (Luhrmann and Roy, 2007; Voth et al., 2007), and the Dot/Icm effectors AnkG, CaeA, and CaeB have already been implicated in this process by distinguished mechanisms. The effector AnkG inhibits host cell apoptosis dependent on the interaction with p32, a host cytoplasmic protein implicated in pathogen-induced apoptosis (Luhrmann et al., 2010). Whereas a mechanism for inhibition of apoptosis by CaeA has not yet been demonstrated, the effector $\mathrm{CaeB}$ co-localizes with the mitochondria and its overexpression reduces the loss of MOMP (mitochondria outer membrane permeabilization) induced by activation of the apoptosis pathway (Klingenbeck et al., 2012).

A role of NLRs and inflammasome activation in the recognition and control of C. burnetii infection has not been demonstrated so far, even though the bacteria is a bona-fide intracellular pathogen that express a functional secretion system, a hallmark for bacterial sensing by macrophages. Still, the capacity of the bacteria to thrive inside the macrophages throughout a slow replicative life cycle suggests that the bacteria might subvert inflammatory responses including the activation of the inflammasome. Future investigations should shed light in a possible role of the inflammasomes in host response to C. burnetii, as well as reveal novel mechanisms of bacterial subversion of the inflammasome and pyroptosis.

\section{CONCLUDING REMARKS}

Activation of the inflammasome is a broad host response that effectively contributes to innate immune response and infection control of a remarkably high number of infectious agents. Activation of this platform leads to inflammasome-dependent secretion of cytokines, induction of pyroptosis and restriction of pathogen replication, by mechanisms that are still obscure. As reviewed here, targeting inflammasome activation is a common evasion strategy of different species of bacterial pathogens. Importantly, different steps of the signaling cascade that leads to inflammasome activation are targeted by bacterial proteins. However, in most cases, the molecular mechanisms underlying inflammasome inhibition are still not fully understood. Few reports identified a direct interaction with the inflammasome effector molecule caspase-1, whereas others provided evidence of an interference with upstream signaling pathway (Figure 2,
Table 1). Moreover, in some cases the inhibition of the inflammasome was verified in the level of caspase- 1 activation and IL- $1 \beta$ secretion, without appropriate assessment of inhibition of pyroptosis. In this scenario, it should be considered that secretion of IL- $1 \beta$ and pyroptosis can be differentially regulated, with caspase11 emerging as a master regulator of these processes. The contribution of caspase-11 in inflammasome activation in response to pathogens is possibly underscored because published literature on the activation of caspase- 1 has been widely assessed using C57BL/6 mice double knockout for both caspase-1 and caspase11 (Kayagaki et al., 2011). In this scenario, it will be important to reevaluate if the reported suppression of the inflammasome by bacterial proteins reviewed herein occur via inhibition of the canonical (caspase-1-dependent, caspase-11-independent) or non-canonical (caspase-11-dependent only) inflammasome. Finally, it is important to emphasize that dysfunctions on inflammasome signaling is intrinsically connected to the onset of diverse chronic inflammatory metabolically and autoimmune syndromes. Understanding the molecular mechanisms of pathogen subversion strategies for suppression of the inflammasome activation and elucidate how they specifically affect inflammasome responses will be critical to a comprehensive understanding of the bacterial pathogenesis and host response. Importantly, it may provide clues for the advance in the development of effective therapeutics to uncontrolled inflammation associated to systemic infections and chronic inflammatory diseases.

\section{ACKNOWLEDGMENTS}

We apologize to our colleagues whose papers we were unable to cite due to space limitations. We thank members of the Zamboni lab and Kenneth Stapleford, for discussions and critical reading of the manuscript. Work in our laboratory is supported by grants from the Fundação de Amparo a Pesquisa do Estado de São Paulo (FAPESP) and Instituto Nacional de Ciência e Tecnologia em Vacinas (INCTV/CNPq) and Fundação de Amparo ao Ensino, Pesquisa e Assistência do Hospital das Clínicas da FMRP/USP (FAEPA).

\section{REFERENCES}

Aachoui, Y., Leaf, I. A., Hagar, J. A., Fontana, M. F., Campos, C. G., Zak, D. E., et al. (2013). Caspase-11 protects against bacteria that escape the vacuole. Science 339, 975-978. doi: 10.1126/science.1230751

Abdul-Sater, A. A., Koo, E., Hacker, G., and Ojcius, D. M. (2009). Inflammasomedependent caspase-1 activation in cervical epithelial cells stimulates growth of the intracellular pathogen Chlamydia trachomatis. J. Biol. Chem. 284, 26789-26796. doi: 10.1074/jbc.M109.026823

Abdul-Sater, A. A., Said-Sadier, N., Padilla, E. V., and Ojcius, D. M. (2010). Chlamydial infection of monocytes stimulates IL-1beta secretion through activation of the NLRP3 inflammasome. Microbes Infect. 12, 652-661. doi: 10.1016/j.micinf.2010.04.008

Abu-Zant, A., Jones, S., Asare, R., Suttles, J., Price, C., Graham, J., et al. (2007). Anti-apoptotic signalling by the Dot/Icm secretion system of L. pneumophila. Cell. Microbiol. 9, 246-264. doi: 10.1111/j.1462-5822.2006.00785.x

Abu-Zant, A., Santic, M., Molmeret, M., Jones, S., Helbig, J., and Abu Kwaik, Y. (2005). Incomplete activation of macrophage apoptosis during intracellular replication of Legionella pneumophila. Infect. Immun. 73, 5339-5349. doi: 10.1128/IAI.73.9.5339-5349.2005

Akhter, A., Gavrilin, M. A., Frantz, L., Washington, S., Ditty, C., Limoli, D., et al. (2009). Caspase-7 activation by the Nlrc4/Ipaf inflammasome restricts Legionella pneumophila infection. PLoS Pathog. 5:e1000361. doi: 10.1371/journal.ppat. 1000361 
Amer, A., Franchi, L., Kanneganti, T. D., Body-Malapel, M., Ozoren, N., Brady, G., et al. (2006). Regulation of Legionella phagosome maturation and infection through flagellin and host Ipaf. J. Biol. Chem. 281, 35217-35223. doi: 10.1074/jbc.M604933200

Ashida, H., Ogawa, M., Mimuro, H., Kobayashi, T., Sanada, T., and Sasakawa, C. (2011). Shigella are versatile mucosal pathogens that circumvent the host innate immune system. Curr. Opin. Immunol. 23, 448-455. doi: 10.1016/j.coi.2011.06.001

Atianand, M. K., Duffy, E. B., Shah, A., Kar, S., Malik, M., and Harton, J. A. (2011). Francisella tularensis reveals a disparity between human and mouse NLRP3 inflammasome activation. J. Biol. Chem. 286, 39033-39042. doi: 10.1074/jbc.M111.244079

Barker, J. R., Chong, A., Wehrly, T. D., Yu, J. J., Rodriguez, S. A., Liu, J., et al. (2009). The Francisella tularensis pathogenicity island encodes a secretion system that is required for phagosome escape and virulence. Mol. Microbiol. 74, 1459-1470. doi: 10.1111/j.1365-2958.2009.06947.x

Barry, A. O., Boucherit, N., Mottola, G., Vadovic, P., Trouplin, V., Soubeyran, P., et al. (2012). Impaired stimulation of p38alpha-MAPK/Vps41HOPS by LPS from pathogenic Coxiella burnetii prevents trafficking to microbicidal phagolysosomes. Cell Host Microbe 12, 751-763. doi: 10.1016/j.chom.2012.10.015

Barry, K. C., Fontana, M. F., Portman, J. L., Dugan, A. S., and Vance, R. E. (2013). IL-lalpha signaling initiates the inflammatory response to virulent Legionella pneumophila in vivo. J. Immunol. 190, 6329-6339. doi: 10.4049/jimmunol.1300100

Bergounioux, J., Elisee, R., Prunier, A. L., Donnadieu, F., Sperandio, B., Sansonetti, P., et al. (2012). Calpain activation by the Shigella flexneri effector VirA regulates key steps in the formation and life of the bacterium's epithelial niche. Cell Host Microbe 11, 240-252. doi: 10.1016/j.chom.2012.01.013

Bergsbaken, T., and Cookson, B. T. (2007). Macrophage activation redirects yersinia-infected host cell death from apoptosis to caspase-1-dependent pyroptosis. PLoS Pathog. 3:e161. doi: 10.1371/journal.ppat.0030161

Betts, H. J., Wolf, K., and Fields, K. A. (2009). Effector protein modulation of host cells: examples in the Chlamydia spp. arsenal. Curr. Opin. Microbiol. 12, 81-87. doi: 10.1016/j.mib.2008.11.009

Brodsky, I. E., and Medzhitov, R. (2008). Reduced secretion of YopJ by Yersinia limits in vivo cell death but enhances bacterial virulence. PLoS Pathog. 4:e1000067. doi: 10.1371/journal.ppat.1000067

Brodsky, I. E., Palm, N. W., Sadanand, S., Ryndak, M. B., Sutterwala, F. S., Flavell, R. A., et al. (2010). A Yersinia effector protein promotes virulence by preventing inflammasome recognition of the type III secretion system. Cell Host Microbe 7, 376-387. doi: 10.1016/j.chom.2010.04.009

Broms, J. E., Meyer, L., Lavander, M., Larsson, P., and Sjostedt, A. (2012). DotU and VgrG, core components of type VI secretion systems, are essential for Francisella LVS pathogenicity. PLOS ONE 7:e34639. doi: 10.1371/journal.pone.0034639

Broms, J. E., Sjostedt, A., and Lavander, M. (2010). The role of the Francisella Tularensis pathogenicity island in type vi secretion, intracellular survival, and modulation of host cell signaling. Front. Microbiol. 1:136. doi: $10.3389 /$ fmicb. 2010.00136

Broz, P., Ruby, T., Belhocine, K., Bouley, D. M., Kayagaki, N., Dixit, V. M., et al. (2012). Caspase-11 increases susceptibility to Salmonella infection in the absence of caspase-1. Nature 490, 288-291. doi: 10.1038/nature11419

Burdette, D. L., Seemann, J., and Orth, K. (2009). Vibrio VopQ induces PI3kinase-independent autophagy and antagonizes phagocytosis. Mol. Microbiol. 73, 639-649. doi: 10.1111/j.1365-2958.2009.06798.x

Byrne, B. G., Dubuisson, J. F., Joshi, A. D., Persson, J. J., and Swanson, M. S. (2013). Inflammasome components coordinate autophagy and pyroptosis as macrophage responses to infection. MBio 4:e00620-e00612. doi: 10.1128/mBio.00620-12

Carneiro, L. A., Travassos, L. H., Soares, F., Tattoli, I., Magalhaes, J. G., Bozza, M. T., et al. (2009). Shigella induces mitochondrial dysfunction and cell death in nonmyleoid cells. Cell Host Microbe 5, 123-136. doi: 10.1016/j.chom.2008.12.011

Case, C. L., Kohler, L. J., Lima, J. B., Strowig, T., De Zoete, M. R., Flavell, R. A., et al. (2013). Caspase-11 stimulates rapid flagellin-independent pyroptosis in response to Legionella pneumophila. Proc. Natl. Acad. Sci. U.S.A. 110, 1851-1856. doi: 10.1073/pnas.1211521110

Case, C. L., Shin, S., and Roy, C. R. (2009). Asc and Ipaf Inflammasomes direct distinct pathways for caspase-1 activation in response to Legionella pneumophila. Infect. Immun. 77, 1981-1991. doi: 10.1128/IAI.01382-08
Casson, C. N., Copenhaver, A. M., Zwack, E. E., Nguyen, H. T., Strowig, T., Javdan, B., et al. (2013). Caspase-11 activation in response to bacterial secretion systems that access the host cytosol. PLoS Pathog. 9:e1003400. doi: 10.1371/journal.ppat. 1003400

Chen, A. L., Johnson, K. A., Lee, J. K., Sutterlin, C., and Tan, M. (2012). CPAF: a Chlamydial protease in search of an authentic substrate. PLoS Pathog. 8:e1002842. doi: 10.1371/journal.ppat.1002842

Chen, Y., Smith, M. R., Thirumalai, K., and Zychlinsky, A. (1996). A bacterial invasin induces macrophage apoptosis by binding directly to ICE. EMBO J. 15, 3853-3860.

Cheng, W., Shivshankar, P., Li, Z., Chen, L., Yeh, I. T., and Zhong, G. (2008). Caspase-1 contributes to Chlamydia trachomatis-induced upper urogenital tract inflammatory pathologies without affecting the course of infection. Infect. Immun. 76, 515-522. doi: 10.1128/IAI.01064-07

Choy, A., Dancourt, J., Mugo, B., O'connor, T. J., Isberg, R. R., Melia, T. J., et al. (2012). The Legionella effector RavZ inhibits host autophagy through irreversible Atg8 deconjugation. Science 338, 1072-1076. doi: 10.1126/science. 1227026

Christian, J., Vier, J., Paschen, S. A., and Hacker, G. (2010). Cleavage of the NFkappaB family protein p65/RelA by the chlamydial protease-like activity factor (CPAF) impairs proinflammatory signaling in cells infected with Chlamydiae. J. Biol. Chem. 285, 41320-41327. doi: 10.1074/jbc.M110.152280

Clarke, M., Lohan, A. J., Liu, B., Lagkouvardos, I., Roy, S., Zafar, N., et al. (2013). Genome of Acanthamoeba castellanii highlights extensive lateral gene transfer and early evolution of tyrosine kinase signaling. Genome Biol. 14:R11. doi: 10.1186/gb-2013-14-2-r11

Coers, J., Vance, R. E., Fontana, M. F., and Dietrich, W. F. (2007). Restriction of Legionella pneumophila growth in macrophages requires the concerted action of cytokine and Naip5/Ipaf signalling pathways. Cell. Microbiol. 9, 2344-2357. doi: 10.1111/j.1462-5822.2007.00963.x

Cohen, T. S., and Prince, A. S. (2013). Activation of inflammasome signaling mediates pathology of acute P. aeruginosa pneumonia. J. Clin. Invest. 123, 1630-1637. doi: 10.1172/JCI66142

Cookson, B. T., and Brennan, M. A. (2001). Pro-inflammatory programmed cell death. Trends Microbiol. 9, 113-114. doi: 10.1016/S0966-842X(00)01936-3

Dong, F., Su, H., Huang, Y., Zhong, Y., and Zhong, G. (2004). Cleavage of host keratin 8 by a Chlamydia-secreted protease. Infect. Immun. 72, 3863-3868. doi: 10.1128/IAI.72.7.3863-3868.2004

Dotson, R. J., Rabadi, S. M., Westcott, E. L., Bradley, S., Catlett, S. V., Banik, S., et al. (2013). Repression of inflammasome by Francisella tularensis during early stages of infection. J. Biol. Chem. 288, 23844-23857. doi: 10.1074/jbc.M113.490086

Eitel, J., Meixenberger, K., Van Laak, C., Orlovski, C., Hocke, A., Schmeck, B., et al. (2012). Racl regulates the NLRP3 inflammasome which mediates IL-1beta production in Chlamydophila pneumoniae infected human mononuclear cells. PLoS ONE 7:e30379. doi: 10.1371/journal.pone.0030379

Engel, J., and Balachandran, P. (2009). Role of Pseudomonas aeruginosa type III effectors in disease. Curr. Opin. Microbiol. 12, 61-66. doi: 10.1016/j.mib.2008.12.007

Ensminger, A. W., Yassin, Y., Miron, A., and Isberg, R. R. (2012). Experimental evolution of Legionella pneumophila in mouse macrophages leads to strains with altered determinants of environmental survival. PLoS Pathog. 8:e1002731. doi: 10.1371/journal.ppat.1002731

Fernandes-Alnemri, T., Yu, J. W., Juliana, C., Solorzano, L., Kang, S., Wu, J., et al. (2010). The AIM2 inflammasome is critical for innate immunity to Francisella tularensis. Nat. Immunol. 11, 385-393. doi: 10.1038/ni.1859

Fink, S. L., and Cookson, B. T. (2006). Caspase-1-dependent pore formation during pyroptosis leads to osmotic lysis of infected host macrophages. Cell. Microbiol. 8, 1812-1825. doi: 10.1111/j.1462-5822.2006.00751.x

Franchi, L., Stoolman, J., Kanneganti, T. D., Verma, A., Ramphal, R., and Nunez G. (2007). Critical role for Ipaf in Pseudomonas aeruginosa-induced caspase-1 activation. Eur. J. Immunol. 37, 3030-3039. doi: 10.1002/eji.200737532

Galle, M., Schotte, P., Haegman, M., Wullaert, A., Yang, H. J., Jin, S., et al. (2008). The Pseudomonas aeruginosa Type III secretion system plays a dual role in the regulation of caspase-1 mediated IL-1beta maturation. J. Cell. Mol. Med. 12, 1767-1776. doi: 10.1111/j.1582-4934.2007. 00190.x

Galluzzi, L., Vitale, I., Abrams, J. M., Alnemri, E. S., Baehrecke, E. H., Blagosklonny, M. V., et al. (2012). Molecular definitions of cell death subroutines: 
recommendations of the nomenclature committee on cell death 2012. Cell Death Differ. 19, 107-120. doi: 10.1038/cdd.2011.96

Gao, L. Y., and Abu Kwaik, Y. (1999). Activation of caspase 3 during Legionella pneumophila-induced apoptosis. Infect. Immun. 67, 4886-4894.

Garau, J., and Gomez, L. (2003). Pseudomonas aeruginosa pneumonia. Curr. Opin. Infect. Dis. 16, 135-143. doi: 10.1097/00001432-200304000-00010

Ge, J., Gong, Y. N., Xu, Y., and Shao, F. (2012). Preventing bacterial DNA release and absent in melanoma 2 inflammasome activation by a Legionella effector functioning in membrane trafficking. Proc. Natl. Acad. Sci. U.S.A. 109, 6193-6198. doi: 10.1073/pnas.1117490109

Gervassi, A., Alderson, M. R., Suchland, R., Maisonneuve, J. F., Grabstein, K. H., and Probst, P. (2004). Differential regulation of inflammatory cytokine secretion by human dendritic cells upon Chlamydia trachomatis infection. Infect. Immun. 72, 7231-7239. doi: 10.1128/IAI.72.12.7231-7239.2004

Ghayur, T., Banerjee, S., Hugunin, M., Butler, D., Herzog, L., Carter, A., et al. (1997). Caspase-1 processes IFN-gamma-inducing factor and regulates LPSinduced IFN-gamma production. Nature 386, 619-623. doi: 10.1038/386619a0

Green, D. R., Ferguson, T., Zitvogel, L., and Kroemer, G. (2009). Immunogenic and tolerogenic cell death. Nat. Rev. Immunol. 9, 353-363. doi: 10.1038/ nri2545

Grobner, S., Adkins, I., Schulz, S., Richter, K., Borgmann, S., Wesselborg, S., et al. (2007). Catalytically active Yersinia outer protein P induces cleavage of RIP and caspase- 8 at the level of the DISC independently of death receptors in dendritic cells. Apoptosis 12, 1813-1825. doi: 10.1007/s10495-007-0100-x

Gu, Y., Kuida, K., Tsutsui, H., Ku, G., Hsiao, K., Fleming, M. A., et al. (1997). Activation of interferon-gamma inducing factor mediated by interleukin1beta converting enzyme. Science 275, 206-209. doi: 10.1126/science.275. 5297.206

Hagar, J. A., Powell, D. A., Aachoui, Y., Ernst, R. K., and Miao, E. A. (2013). Cytoplasmic LPS activates caspase-11: implications in TLR4-independent endotoxic shock. Science 341, 1250-1253. doi: 10.1126/science.1240988

Higa, N., Toma, C., Koizumi, Y., Nakasone, N., Nohara, T., Masumoto, J., et al. (2013). Vibrio parahaemolyticus effector proteins suppress inflammasome activation by interfering with host autophagy signaling. PLoS Pathog. 9:e1003142. doi: 10.1371/journal.ppat.1003142

Hilbi, H., Moss, J. E., Hersh, D., Chen, Y., Arondel, J., Banerjee, S., et al. (1998). Shigella-induced apoptosis is dependent on caspase-1 which binds to IpaB. J. Biol. Chem. 273, 32895-32900. doi: 10.1074/jbc.273.49.32895

Huang, M. T., Mortensen, B. L., Taxman, D. J., Craven, R. R., Taft-Benz, S., Kijek, T. M., et al. (2010). Deletion of ripA alleviates suppression of the inflammasome and MAPK by Francisella tularensis. J. Immunol. 185, 5476-5485. doi: 10.4049/jimmunol.1002154

Hubber, A., and Roy, C. R. (2010). Modulation of host cell function by Legionella pneumophila type IV effectors. Annu. Rev. Cell Dev. Biol. 26, 261-283. doi: 10.1146/annurev-cellbio-100109-104034

Inoue, M., Williams, K. L., Oliver, T., Vandenabeele, P., Rajan, J. V., Miao, E. A., et al. (2012). Interferon-beta therapy against EAE is effective only when development of the disease depends on the NLRP3 inflammasome. Sci. Signal. 5, ra38. doi: $10.1126 /$ scisignal.2002767

Jones, J. W., Kayagaki, N., Broz, P., Henry, T., Newton, K., O'rourke, K., et al. (2010). Absent in melanoma 2 is required for innate immune recognition of Francisella tularensis. Proc. Natl. Acad. Sci. U.S.A. 107, 9771-9776. doi: 10.1073/pnas.1003738107

Jorgensen, I., Bednar, M. M., Amin, V., Davis, B. K., Ting, J. P., Mccafferty, D. G., et al. (2011). The Chlamydia protease CPAF regulates host and bacterial proteins to maintain pathogen vacuole integrity and promote virulence. Cell Host Microbe 10, 21-32. doi: 10.1016/j.chom.2011.06.008

Kang, S. J., Wang, S., Kuida, K., and Yuan, J. (2002). Distinct downstream pathways of caspase-11 in regulating apoptosis and cytokine maturation during septic shock response. Cell Death Differ. 9, 1115-1125. doi: 10.1038/sj.cdd.4401087

Karmakar, M., Sun, Y., Hise, A. G., Rietsch, A., and Pearlman, E. (2012). Cutting edge: IL-1beta processing during Pseudomonas aeruginosa infection is mediated by neutrophil serine proteases and is independent of NLRC4 and caspase-1. J. Immunol. 189, 4231-4235. doi: 10.4049/jimmunol.1201447

Kayagaki, N., Warming, S., Lamkanfi, M., Vande Walle, L., Louie, S., Dong, J., et al. (2011). Non-canonical inflammasome activation targets caspase-11. Nature 479, 117-121. doi: 10.1038/nature10558

Kayagaki, N., Wong, M. T., Stowe, I. B., Ramani, S. R., Gonzalez, L. C., Akashi-Takamura, S., et al. (2013). Noncanonical inflammasome activation by intracellular LPS independent of TLR4. Science 341, 1246-1249. doi: 10.1126/science. 1240248

Klingenbeck, L., Eckart, R. A., Berens, C., and Luhrmann, A. (2012). The Coxiella burnetii type IV secretion system substrate CaeB inhibits intrinsic apoptosis at the mitochondrial level. Cell. Microbiol 15, 675-687. doi: 10.1111/cmi.12066

Kobayashi, T., Ogawa, M., Sanada, T., Mimuro, H., Kim, M., Ashida, H., et al. (2013). The Shigella OspC3 effector inhibits caspase-4, antagonizes inflammatory cell death, and promotes epithelial infection. Cell Host Microbe 13, 570-583. doi: 10.1016/j.chom.2013.04.012

Kubori, T., Shinzawa, N., Kanuka, H., and Nagai, H. (2010). Legionella metaeffector exploits host proteasome to temporally regulate cognate effector. PLoS Pathog. 6:e1001216. doi: 10.1371/journal.ppat.1001216

Kumar, Y., and Valdivia, R. H. (2008). Actin and intermediate filaments stabilize the Chlamydia trachomatis vacuole by forming dynamic structural scaffolds. Cell Host Microbe 4, 159-169. doi: 10.1016/j.chom.2008.05.018

Kung, V. L., Khare, S., Stehlik, C., Bacon, E. M., Hughes, A. J., and Hauser, A. R. (2012). An rhs gene of Pseudomonas aeruginosa encodes a virulence protein that activates the inflammasome. Proc. Natl. Acad. Sci. U.S.A. 109, 1275-1280. doi: 10.1073/pnas.1109285109

Laguna, R. K., Creasey, E. A., Li, Z., Valtz, N., and Isberg, R. R. (2006). A Legionella pneumophila-translocated substrate that is required for growth within macrophages and protection from host cell death. Proc. Natl. Acad. Sci. U.S.A. 103, 18745-18750. doi: 10.1073/pnas.0609012103

Lamkanfi, M., and Dixit, V. M. (2012). Inflammasomes and their roles in health and disease. Annu. Rev. Cell Dev. Biol. 28, 137-161. doi: 10.1146/annurev-cellbio101011-155745

Larock, C. N., and Cookson, B. T. (2012). The Yersinia virulence effector YopM binds caspase-1 to arrest inflammasome assembly and processing. Cell Host Microbe 12, 799-805. doi: 10.1016/j.chom.2012.10.020

Larsson, P., Oyston, P. C., Chain, P., Chu, M. C., Duffield, M., Fuxelius, H. H., et al. (2005). The complete genome sequence of Francisella tularensis, the causative agent of tularemia. Nat. Genet. 37, 153-159. doi: 10.1038/ ng1499

Lightfield, K. L., Persson, J., Brubaker, S. W., Witte, C. E., Von Moltke, J., Dunipace, E. A., et al. (2008). Critical function for Naip5 in inflammasome activation by a conserved carboxy-terminal domain of flagellin. Nat. Immunol. 9, 1171-1178. doi: 10.1038/ni.1646

Lilo, S., Zheng, Y., and Bliska, J. B. (2008). Caspase-1 activation in macrophages infected with Yersinia pestis KIM requires the type III secretion system effector YopJ. Infect. Immun. 76, 3911-3923. doi: 10.1128/IAI. 01695-07

Lima-Junior, D. S., Costa, D. L., Carregaro, V., Cunha, L. D., Silva, A. L., Mineo, T. W., et al. (2013). Inflammasome-derived IL-1beta production induces nitric oxide-mediated resistance to Leishmania. Nat. Med. 19, 909-915. doi: 10.1038/nm.3221

Lu, H., Shen, C., and Brunham, R. C. (2000). Chlamydia trachomatis infection of epithelial cells induces the activation of caspase- 1 and release of mature IL-18. J. Immunol. 165, 1463-1469.

Luhrmann, A., Nogueira, C. V., Carey, K. L., and Roy, C. R. (2010). Inhibition of pathogen-induced apoptosis by a Coxiella burnetii type IV effector protein. Proc. Natl. Acad. Sci. U.S.A. 107, 18997-19001. doi: 10.1073/pnas.1004380107

Luhrmann, A., and Roy, C. R. (2007). Coxiella burnetii inhibits activation of host cell apoptosis through a mechanism that involves preventing cytochrome c release from mitochondria. Infect. Immun. 75, 5282-5289. doi: 10.1128/IAI.00863-07

Makino, K., Oshima, K., Kurokawa, K., Yokoyama, K., Uda, T., Tagomori, K., et al. (2003). Genome sequence of Vibrio parahaemolyticus: a pathogenic mechanism distinct from that of V cholerae. Lancet 361, 743-749. doi: 10.1016/S01406736(03)12659-1

Mariathasan, S., Weiss, D. S., Dixit, V. M., and Monack, D. M. (2005). Innate immunity against Francisella tularensis is dependent on the ASC/caspase-1 axis. J. Exp. Med. 202, 1043-1049. doi: 10.1084/jem.20050977

Mariathasan, S., Weiss, D. S., Newton, K., Mcbride, J., O’rourke, K., Roose-Girma, M., et al. (2006). Cryopyrin activates the inflammasome in response to toxins and ATP. Nature 440, 228-232. doi: 10.1038/nature04515

Martinon, F., Burns, K., and Tschopp, J. (2002). The inflammasome: a molecular platform triggering activation of inflammatory caspases and processing of proIL-beta. Mol. Cell 10, 417-426. doi: 10.1016/S1097-2765(02) 00599-3 
Massis, L. M., and Zamboni, D. S. (2011). Innate immunity to legionella pneumophila. Front. Microbiol. 2:109. doi: 10.3389/fmicb.2011.00109

McDonough, J. A., Newton, H. J., and Roy, C. R. (2012). Coxiella burnetii secretion systems. Adv. Exp. Med. Biol. 984, 171-197. doi: 10.1007/978-94-007-4315-1_9

Meibom, K. L., and Charbit, A. (2010). The unraveling panoply of Francisella tularensis virulence attributes. Curr. Opin. Microbiol. 13, 11-17. doi: 10.1016/j.mib.2009.11.007

Miao, E. A., Ernst, R. K., Dors, M., Mao, D. P., and Aderem, A. (2008). Pseudomonas aeruginosa activates caspase 1 through Ipaf. Proc. Natl. Acad. Sci. U.S.A. 105, 2562-2567. doi: 10.1073/pnas.0712183105

Miao, E. A., Leaf, I. A., Treuting, P. M., Mao, D. P., Dors, M., Sarkar, A., et al. (2010a). Caspase-1-induced pyroptosis is an innate immune effector mechanism against intracellular bacteria. Nat. Immunol. 11, 1136-1142. doi: 10.1038/ni.1960

Miao, E. A., Mao, D. P., Yudkovsky, N., Bonneau, R., Lorang, C. G., Warren, S. E., et al. (2010b). Innate immune detection of the type III secretion apparatus through the NLRC4 inflammasome. Proc. Natl. Acad. Sci. U.S.A. 107, 3076-3080. doi: 10.1073/pnas.0913087107

Miao, E. A., Rajan, J. V., and Aderem, A. (2011). Caspase-1-induced pyroptotic cell death. Immunol. Rev. 243, 206-214. doi: 10.1111/j.1600-065X.2011.01044.X

Mills, S. D., Boland, A., Sory, M. P., Van Der Smissen, P., Kerbourch, C., Finlay, B. B., et al. (1997). Yersinia enterocolitica induces apoptosis in macrophages by a process requiring functional type III secretion and translocation mechanisms and involving YopP, presumably acting as an effector protein. Proc. Natl. Acad. Sci. U.S.A. 94, 12638-12643. doi: 10.1073/pnas.94.23.12638

Misawa, T., Takahama, M., Kozaki, T., Lee, H., Zou, J., Saitoh, T., et al. (2013). Microtubule-driven spatial arrangement of mitochondria promotes activation of the NLRP3 inflammasome. Nat. Immunol. 14, 454-460. doi: 10.1038/ ni. 2550

Molmeret, M., Zink, S. D., Han, L., Abu-Zant, A., Asari, R., and Bitar, D. M. (2004). Activation of caspase- 3 by the Dot/Icm virulence system is essential for arrested biogenesis of the Legionella-containing phagosome. Cell Microbiol. 6, 33-48. doi: 10.1046/j.1462-5822.2003.00335.x

Molofsky, A. B., Byrne, B. G., Whitfield, N. N., Madigan, C. A., Fuse, E. T., Tateda, K., et al. (2006). Cytosolic recognition of flagellin by mouse macrophages restricts Legionella pneumophila infection. J. Exp. Med. 203, 1093-1104. doi: 10.1084/jem.20051659

Monack, D. M., Mecsas, J., Bouley, D., and Falkow, S. (1998). Yersinia-induced apoptosis in vivo aids in the establishment of a systemic infection of mice. J. Exp. Med. 188, 2127-2137. doi: 10.1084/jem.188.11.2127

Monack, D. M., Mecsas, J., Ghori, N., and Falkow, S. (1997). Yersinia signals macrophages to undergo apoptosis and YopJ is necessary for this cell death. Proc. Natl. Acad. Sci. U.S.A. 94, 10385-10390. doi: 10.1073/pnas.94.19.10385

Muller, A. J., Hoffmann, C., Galle, M., Van Den Broeke, A., Heikenwalder, M., Falter, L., et al. (2009). The S. Typhimurium effector SopE induces caspase1 activation in stromal cells to initiate gut inflammation. Cell Host Microbe 6, 125-136. doi: 10.1016/j.chom.2009.07.007

Narasaki, C. T., and Toman, R. (2012). Lipopolysaccharide of Coxiella burnetii. Adv. Exp. Med. Biol. 984, 65-90. doi: 10.1007/978-94-007-4315-1_4

Newton, H. J., and Roy, C. R. (2011). The Coxiella burnetii Dot/Icm system creates a comfortable home through lysosomal renovation. MBio 2:e00226-11. doi: 10.1128/mBio.00226-11

Nogueira, C. V., Lindsten, T., Jamieson, A. M., Case, C. L., Shin, S., Thompson, C. B., et al. (2009). Rapid pathogen-induced apoptosis: a mechanism used by dendritic cells to limit intracellular replication of Legionella pneumophila. PLoS Pathog. 5:e1000478. doi: 10.1371/journal.ppat.1000478

Ogawa, M., Handa, Y., Ashida, H., Suzuki, M., and Sasakawa, C. (2008). The versatility of Shigella effectors. Nat. Rev. Microbiol. 6, 11-16. doi: 10.1038/nrmicrol814

Osawa, R., Williams, K. L., and Singh, N. (2011). The inflammasome regulatory pathway and infections: role in pathophysiology and clinical implications. J. Infect. 62, 119-129. doi: 10.1016/j.jinf.2010.10.002

Paschen, S. A., Christian, J. G., Vier, J., Schmidt, F., Walch, A., Ojcius, D. M., et al. (2008). Cytopathicity of Chlamydia is largely reproduced by expression of a single chlamydial protease. J. Cell Biol. 182, 117-127. doi: 10.1083/jcb.200804023

Pederson, K. J., and Barbieri, J. T. (1998). Intracellular expression of the ADP-ribosyltransferase domain of Pseudomonas exoenzyme $\mathrm{S}$ is cytotoxic to eukaryotic cells. Mol. Microbiol. 30, 751-759. doi: 10.1046/j.1365-2958. 1998.01106.x
Peng, K., Broz, P., Jones, J., Joubert, L. M., and Monack, D. (2011). Elevated AIM2mediated pyroptosis triggered by hypercytotoxic Francisella mutant strains is attributed to increased intracellular bacteriolysis. Cell. Microbiol. 13, 1586-1600. doi: 10.1111/j.1462-5822.2011.01643.x

Pereira, M. S., Morgantetti, G. F., Massis, L. M., Horta, C. V., Hori, J. I., and Zamboni, D. S. (2011). Activation of NLRC4 by flagellated bacteria triggers caspase-1-dependent and -independent responses to restrict Legionella pneumophila replication in macrophages and in vivo. J. Immunol. 187, 6447-6455. doi: 10.4049/jimmunol.1003784

Peters, K. N., Dhariwala, M. O., Hughes Hanks, J. M., Brown, C. R., and Anderson, D. M. (2013). Early apoptosis of macrophages modulated by injection of Yersinia pestis YopK promotes progression of primary pneumonic plague. PLoS Pathog. 9:e1003324. doi: 10.1371/journal.ppat.1003324

Phalipon, A., and Sansonetti, P. J. (2007). Shigella's ways of manipulating the host intestinal innate and adaptive immune system: a tool box for survival? Immunol. Cell Biol. 85, 119-129. doi: 10.1038/sj.icb7100025

Philip, N. H., and Brodsky, I. E. (2012). Cell death programs in Yersinia immunity and pathogenesis. Front. Cell. Infect. Microbiol. 2:149. doi: 10.3389/fcimb.2012.00149

Pierini, R., Juruj, C., Perret, M., Jones, C. L., Mangeot, P., Weiss, D. S., et al. (2012). AIM2/ASC triggers caspase-8-dependent apoptosis in Francisellainfected caspase-1-deficient macrophages. Cell Death Differ. 19, 1709-1721. doi: $10.1038 /$ cdd.2012.51

Pirbhai, M., Dong, F., Zhong, Y., Pan, K. Z., and Zhong, G. (2006). The secreted protease factor $\mathrm{CPAF}$ is responsible for degrading pro-apoptotic $\mathrm{BH} 3$-only proteins in Chlamydia trachomatis-infected cells. J. Biol. Chem. 281, 31495-31501. doi: 10.1074/jbc.M602796200

Rathinam, V. A., Jiang, Z., Waggoner, S. N., Sharma, S., Cole, L. E., Waggoner, L., et al. (2010). The AIM2 inflammasome is essential for host defense against cytosolic bacteria and DNA viruses. Nat. Immunol. 11, 395-402. doi: 10.1038/ni. 1864

Ren, T., Zamboni, D. S., Roy, C. R., Dietrich, W. F., and Vance, R. E. (2006). Flagellin-deficient Legionella mutants evade caspase-1- and Naip5mediated macrophage immunity. PLoS Pathog. 2:e18. doi: 10.1371/journal.ppat. 0020018

Ruckdeschel, K., Harb, S., Roggenkamp, A., Hornef, M., Zumbihl, R., Kohler, S., et al. (1998). Yersinia enterocolitica impairs activation of transcription factor NF-kappaB: involvement in the induction of programmed cell death and in the suppression of the macrophage tumor necrosis factor alpha production. J. Exp. Med. 187, 1069-1079. doi: 10.1084/jem.187.7.1069

Ruckdeschel, K., Richter, K., Mannel, O., and Heesemann, J. (2001). Arginine-143 of Yersinia enterocolitica YopP crucially determines isotype-related NF-kappaB suppression and apoptosis induction in macrophages. Infect. Immun. 69, 7652-7662. doi: 10.1128/IAI.69.12.7652-7662.2001

Saitoh, T., Fujita, N., Jang, M. H., Uematsu, S., Yang, B. G., Satoh, T., et al. (2008). Loss of the autophagy protein Atg16L1 enhances endotoxin-induced IL-1beta production. Nature 456, 264-268. doi: 10.1038/nature07383

Sansonetti, P. J., Arondel, J., Cavaillon, J. M., and Huerre, M. (1995). Role of interleukin-1 in the pathogenesis of experimental shigellosis. J. Clin. Invest. 96, 884-892. doi: 10.1172/JCI118135

Sansonetti, P. J., Phalipon, A., Arondel, J., Thirumalai, K., Banerjee, S., Akira, S., et al. (2000). Caspase-1 activation of IL-1beta and IL-18 are essential for Shigella flexneri-induced inflammation. Immunity 12, 581-590. doi: 10.1016/S10747613(00)80209-5

Sato, H., and Frank, D. W. (2004). ExoU is a potent intracellular phospholipase. Mol. Microbiol. 53, 1279-1290. doi: 10.1111/j.1365-2958.2004.04194.x

Schotte, P., Denecker, G., Van Den Broeke, A., Vandenabeele, P., Cornelis, G. R., and Beyaert, R. (2004). Targeting Racl by the Yersinia effector protein YopE inhibits caspase-1-mediated maturation and release of interleukin-1beta. J. Biol. Chem. 279, 25134-25142. doi: 10.1074/jbc.M401245200

Schroeder, G. N., and Hilbi, H. (2008). Molecular pathogenesis of Shigella spp.: controlling host cell signaling, invasion, and death by type III secretion. Clin. Microbiol. Rev. 21, 134-156. doi: 10.1128/CMR.00032-07

Senerovic, L., Tsunoda, S. P., Goosmann, C., Brinkmann, V., Zychlinsky, A., Meissner, F., et al. (2012). Spontaneous formation of IpaB ion channels in host cell membranes reveals how Shigella induces pyroptosis in macrophages. Cell Death Dis. 3, e384. doi: 10.1038/cddis.2012.124

Shannon, J. G., Howe, D., and Heinzen, R. A. (2005). Virulent Coxiella burnetii does not activate human dendritic cells: role of lipopolysaccharide 
as a shielding molecule. Proc. Natl. Acad. Sci. U.S.A. 102, 8722-8727. doi: 10.1073/pnas.0501863102

Silva, G. K., Costa, R. S., Silveira, T. N., Caetano, B. C., Horta, C. V., Gutierrez, F. R., et al. (2013). Apoptosis-associated speck-like protein containing a caspase recruitment domain inflammasomes mediate IL-1beta response and host resistance to trypanosoma cruzi infection. J. Immunol. 191, 3373-3383. doi: 10.4049/jimmunol.1203293

Silveira, T. N., and Zamboni, D. S. (2010). Pore formation triggered by Legionella spp. is an Nlrc4 inflammasome-dependent host cell response that precedes pyroptosis. Infect. Immun. 78, 1403-1413. doi: 10.1128/IAI.00905-09

Sutterwala, F. S., Mijares, L. A., Li, L., Ogura, Y., Kazmierczak, B. I., and Flavell, R. A. (2007). Immune recognition of Pseudomonas aeruginosa mediated by the IPAF/NLRC4 inflammasome. J. Exp. Med. 204, 3235-3245. doi: 10.1084/jem.20071239

Suzuki, T., Franchi, L., Toma, C., Ashida, H., Ogawa, M., Yoshikawa, Y., et al. (2007). Differential regulation of caspase- 1 activation, pyroptosis, and autophagy via Ipaf and ASC in Shigella-infected macrophages. PLoS Pathog. 3:e111. doi: 10.1371/journal.ppat.0030111

Terra, J. K., Cote, C. K., France, B., Jenkins, A. L., Bozue, J. A., Welkos, S. L., et al. (2010). Cutting edge: resistance to Bacillus anthracis infection mediated by a lethal toxin sensitive allele of Nalp1b/Nlrp1b. J. Immunol. 184, 17-20. doi: 10.4049/jimmunol.0903114

Thornberry, N. A., Bull, H. G., Calaycay, J. R., Chapman, K. T., Howard, A. D., Kostura, M. J., et al. (1992). A novel heterodimeric cysteine protease is required for interleukin-1 beta processing in monocytes. Nature 356, 768-774. doi: $10.1038 / 356768 \mathrm{a} 0$

Trosky, J. E., Liverman, A. D., and Orth, K. (2008). Yersinia outer proteins: Yops. Cell. Microbiol. 10, 557-565. doi: 10.1111/j.1462-5822.2007.01109.x

Ulland, T. K., Buchan, B. W., Ketterer, M. R., Fernandes-Alnemri, T., Meyerholz, D. K., Apicella, M. A., et al. (2010). Cutting edge: mutation of Francisella tularensis mviN leads to increased macrophage absent in melanoma 2 inflammasome activation and a loss of virulence. J. Immunol. 185, 2670-2674. doi: 10.4049/jimmunol.1001610

Valdivia, R. H. (2008). Chlamydia effector proteins and new insights into chlamydial cellular microbiology. Curr. Opin. Microbiol. 11, 53-59. doi: 10.1016/j.mib.2008.01.003

Van Schaik, E. J., Chen, C., Mertens, K., Weber, M. M., and Samuel, J. E. (2013). Molecular pathogenesis of the obligate intracellular bacterium Coxiella burnetii. Nat. Rev. Microbiol. 11, 561-573. doi: 10.1038/nrmicro3049

Vazquez, C. L., and Colombo, M. I. (2010). Coxiella burnetii modulates Beclin 1 and $\mathrm{Bcl}-2$, preventing host cell apoptosis to generate a persistent bacterial infection. Cell Death Differ. 17, 421-438. doi: 10.1038/cdd.2009.129

Voth, D. E., and Heinzen, R. A. (2009). Sustained activation of Akt and Erk1/2 is required for Coxiella burnetii antiapoptotic activity. Infect. Immun. 77, 205-213. doi: 10.1128/IAI.01124-08

Voth, D. E., Howe, D., and Heinzen, R. A. (2007). Coxiella burnetii inhibits apoptosis in human THP-1 cells and monkey primary alveolar macrophages. Infect. Immun. 75, 4263-4271. doi: 10.1128/IAI.00594-07

Weber, M. M., Chen, C., Rowin, K., Mertens, K., Galvan, G., Zhi, H., et al. (2013). Identification of C. burnetii type IV secretion substrates required for intracellular replication and Coxiella-containing vacuole formation. J. Bacteriol. 195, 3914-3924. doi: 10.1128/JB.00071-13
Zamboni, D. S., Campos, M. A., Torrecilhas, A. C., Kiss, K., Samuel, J. E., Golenbock, D. T., et al. (2004). Stimulation of toll-like receptor 2 by Coxiella burnetii is required for macrophage production of pro-inflammatory cytokines and resistance to infection. J. Biol. Chem. 279, 54405-54415. doi: 10.1074/jbc.M410340200

Zamboni, D. S., Kobayashi, K. S., Kohlsdorf, T., Ogura, Y., Long, E. M., Vance, R. E., et al. (2006). The Bircle cytosolic pattern-recognition receptor contributes to the detection and control of Legionella pneumophila infection. Nat. Immunol. 7, 318-325. doi: 10.1038/ni1305

Zhao, Y., Yang, J., Shi, J., Gong, Y. N., Lu, Q., Xu, H., et al. (2011). The NLRC4 inflammasome receptors for bacterial flagellin and type III secretion apparatus. Nature 477, 596-600. doi: 10.1038/nature10510

Zheng, Y., Lilo, S., Brodsky, I. E., Zhang, Y., Medzhitov, R., Marcu, K. B., et al. (2011). A Yersinia effector with enhanced inhibitory activity on the NF-kappaB pathway activates the NLRP3/ASC/caspase-1 inflammasome in macrophages. PLoS Pathog. 7:e1002026. doi: 10.1371/journal.ppat. 1002026

Zheng, Y., Lilo, S., Mena, P., and Bliska, J. B. (2012). YopJ-induced caspase-1 activation in Yersinia-infected macrophages: independent of apoptosis, linked to necrosis, dispensable for innate host defense. PLoS ONE 7:e36019. doi: 10.1371/journal.pone.0036019

Zhong, G., Fan, P., Ji, H., Dong, F., and Huang, Y. (2001). Identification of a chlamydial protease-like activity factor responsible for the degradation of host transcription factors. J. Exp. Med. 193, 935-942. doi: 10.1084/jem. 193.8.935

Zhu, W., Hammad, L. A., Hsu, F., Mao, Y., and Luo, Z. Q. (2013). Induction of caspase 3 activation by multiple Legionella pneumophila Dot/Icm substrates. Cell. Microbiol. 15, 1783-1795. doi: 10.1111/cmi.12157

Zink, S. D., Pedersen, L., Cianciotto, N. P., and Abu-Kwaik, Y. (2002). The Dot/Icm type IV secretion system of Legionella pneumophila is essential for the induction of apoptosis in human macrophages. Infect. Immun. 70, 1657-1663. doi: 10.1128/IAI.70.3.1657-1663.2002

Conflict of Interest Statement: The authors declare that the research was conducted in the absence of any commercial or financial relationships that could be construed as a potential conflict of interest.

Received: 20 September 2013; accepted: 23 October 2013; published online: 26 November 2013.

Citation: Cunha LD and Zamboni DS (2013) Subversion of inflammasome activation and pyroptosis by pathogenic bacteria. Front. Cell. Infect. Microbiol. 3:76. doi: 10.3389/fcimb.2013.00076

This article was submitted to the journal Frontiers in Cellular and Infection Microbiology.

Copyright (c) 2013 Cunha and Zamboni. This is an open-access article distributed under the terms of the Creative Commons Attribution License (CC BY). The use, distribution or reproduction in other forums is permitted, provided the original author(s) or licensor are credited and that the original publication in this journal is cited, in accordance with accepted academic practice. No use, distribution or reproduction is permitted which does not comply with these terms. 